\title{
The integrated water balance and soil data set of the Rollesbroich hydrological observatory
}

\author{
Wei Qu, Heye R. Bogena, Johan A. Huisman, Marius Schmidt, Ralf Kunkel, Ansgar Weuthen, \\ Henning Schiedung, Bernd Schilling, Jürgen Sorg, and Harry Vereecken \\ Agrosphere Institute (IBG-3), Forschungszentrum Jülich GmbH, 52425 Jülich, Germany \\ Correspondence to: Heye R. Bogena (h.bogena@fz-juelich.de)
}

Received: 25 April 2016 - Published in Earth Syst. Sci. Data Discuss.: 6 June 2016

Revised: 22 September 2016 - Accepted: 27 September 2016 - Published: 20 October 2016

\begin{abstract}
The Rollesbroich headwater catchment located in western Germany is a densely instrumented hydrological observatory and part of the TERENO (Terrestrial Environmental Observatories) initiative. The measurements acquired in this observatory present a comprehensive data set that contains key hydrological fluxes in addition to important hydrological states and properties. Meteorological data (i.e., precipitation, air temperature, air humidity, radiation components, and wind speed) are continuously recorded and actual evapotranspiration is measured using the eddy covariance technique. Runoff is measured at the catchment outlet with a gauging station. In addition, spatiotemporal variations in soil water content and temperature are measured at high resolution with a wireless sensor network (SoilNet). Soil physical properties were determined using standard laboratory procedures from samples taken at a large number of locations in the catchment. This comprehensive data set can be used to validate remote sensing retrievals and hydrological models, to improve the understanding of spatial temporal dynamics of soil water content, to optimize data assimilation and inverse techniques for hydrological models, and to develop upscaling and downscaling procedures of soil water content information. The complete data set is freely available online (http://www.tereno.net, doi:10.5880/TERENO.2016.001, doi:10.5880/TERENO.2016.004, doi:10.5880/TERENO.2016.003) and additionally referenced by three persistent identifiers securing the long-term data and metadata availability.
\end{abstract}

\section{Introduction}

Climate and land use changes are taking place on different spatial and temporal scales, affecting all environmental compartments. Soil water content is known to be a major control for evapotranspiration, precipitation-runoff response, and heat transfer between soil and atmosphere, and it plays an essential role for climate projections, weather and flood forecasting, water and soil resources management, agriculture, and water quality control (Albertson and Kiely, 2001; Betts et al., 1996; Crow et al., 2005; Robinson et al., 2008; Vereecken et al., 2008; Western et al., 2002). However, the highly heterogeneous pattern of soil water content leading to complex and scale-dependent patterns of water, energy, and matter fluxes makes it challenging to predict terrestrial system responses for both scientists and policymakers (Jaeger and Seneviratne, 2011; Seneviratne et al., 2010). Therefore, integrated observations of soil water content and the exchange of water and heat between the soil, vegetation, and atmosphere are critical to improving our understanding of the terrestrial system response to changes in climatic conditions and land management (Dirnbock et al., 2003; Foley et al., 1998; Hinzman et al., 2005; Refsgaard, 1997; Seneviratne et al., 2010; Guo and Lin, 2016) and serve as key data in validating remote sensing data products (e.g., Rötzer et al., 2014; Cosh et al., 2016).

To this end, a network of integrated observation platforms has been established in the framework of the Terrestrial Environmental Observatories (TERENO) initiative (funded by Helmholtz Association of German Research Centers) to investigate the consequences of global change on terrestrial ecosystems (Bogena et al., 2012; Zacharias et al., 2011). TERENO aims to collect long-term time series of system 
states and fluxes using state-of-the-art monitoring technologies, e.g., to close the local water balance (Graf et al., 2014) and to investigate of the effects of deforestation on water, energy, and matter fluxes in an integrative manner (Bogena et al., 2015). The Rollesbroich grassland experimental catchment is part of the TERENO observatory Eifel/Lower Rhine Valley. All components of the water balance (e.g., precipitation, evapotranspiration, runoff, soil water content) are continuously monitored using state-of-the-art instrumentation, providing detailed information about the spatial and temporal variation of the local water cycle for the evaluation of hydrological models (Bloschl and Sivapalan, 1995; Thompson et al., 2011). In addition, using water balance data within the context of hydrological modeling helps to determine measurement errors, to diagnose such errors, and to avoid misattribution of water balance components (Evett et al., 2012; Kampf and Burges, 2010; Vasilenko, 2004). Finally, quantification of water balance components is helpful for understanding the availability of water resources, the potential of hydrologic extremes such as floods and droughts, and the interactions between the land surface and the atmosphere (Flerchinger and Cooley, 2000; Huntington, 2006).

Here, we present a comprehensive hydrological data set recorded in the Rollesbroich catchment from 1 May 2011 to 31 December 2013. The hydrological data set includes time series of meteorological forcing (i.e., precipitation, air temperature, air humidity, radiation components, and wind speed), actual evapotranspiration, runoff, as well as soil water content data from a wireless sensor network (SoilNet). In addition, information on soil physical properties and vegetation (i.e., leaf area index, LAI) useful for the parameterization of hydrological models is presented.

\section{Catchment description}

The Rollesbroich catchment $\left(50^{\circ} 37^{\prime} 27^{\prime \prime} \mathrm{N}, 6^{\circ} 18^{\prime} 17^{\prime \prime} \mathrm{E}\right)$ is located in the Eifel mountain range and covers an area of about 40 ha with altitudes ranging from 474 to $518 \mathrm{~m}$ a.s.l. The catchment mean annual air temperature and precipitation are $7.7^{\circ} \mathrm{C}$ and $103.3 \mathrm{~cm}$, respectively, for the period from 1981 to 2001 . These data are recorded by a meteorological station operated by the North Rhine-Westphalian State Environment Agency with a distance of $4 \mathrm{~km}$ from the Rollesbroich catchment. The dominant soils are Cambisols in the southern part and Stagnosols in the northern part of the catchment. The grassland vegetation is dominated by perennial ryegrass (Lolium perenne) and smooth meadow grass (Poa pratensis). The average slope within the hydrological observatory is $1.63^{\circ}$ (min.: $0.35^{\circ}$, $\max .: 3.12^{\circ}$ ).

\section{Methods}

\subsection{Meteorological data}

Meteorological data, i.e., precipitation, air temperature, air humidity, radiation components, and wind speed, were recorded at a micrometeorological tower located in the center of the almost flat terrain in the southern part of the Rollesbroich catchment (see Fig. 1). Wind speed was obtained with a sonic anemometer at $2.6 \mathrm{~m}$ above surface (CSAT3, Campbell Scientific, Inc., Logan, USA). The $\mathrm{H}_{2} \mathrm{O}$ concentration was measured using an open-path infrared gas analyzer (LI7500, LI-COR Inc., Lincoln, NE, USA) at the same height. Air temperature and humidity (HMP45C, Vaisala Inc., Helsinki, Finland) were measured at $2.6 \mathrm{~m}$ height above the ground surface. Incoming short- and long-wave radiation were determined using a NR01 four-component net radiometer (Hukseflux Thermal Sensors, Delft, Netherlands). Data of all instruments including diagnostic data were recorded with a logger (CR3000, Campbell Scientific, Logan, UT, USA) at $20 \mathrm{~Hz}$. Precipitation was recorded by a heated Hellmanntype tipping bucket rain gauge (eco-Tech $\mathrm{GmbH}$, Bonn, Germany). In July 2013, a weight-based precipitation gauge (Pluvio $^{2}$, OTT Hydromet GmbH, Kempten, Germany) was added to the nearby backup climate station, providing more accurate measurements of all precipitation types. Both precipitation gauges were installed at a height of $1 \mathrm{~m}$ above ground surface as recommended by the German Weather Service for sites at an elevation above $500 \mathrm{~m}$ a.s.l. with occasional heavy snowfall. All meteorological measurements were stored at $10 \mathrm{~min}$ intervals.

\subsection{Actual evapotranspiration}

Latent heat flux was obtained by the eddy covariance (EC) technique. The EC post-processing software TK3.1 (Mauder and Foken, 2011) was used to calculate latent heat flux from the vertical wind velocity obtained by the sonic anemometer (CSAT3, Campbell Scientific, Inc., Logan, USA) and water vapor density obtained by an infrared gas analyzer (LI7500, LI-COR Inc., Lincoln, NE, USA). The processing and quality assurance of the EC data followed the corresponding TERENO strategy presented in Mauder et al. (2013). Actual evapotranspiration was calculated from the latent heat flux using

$$
\begin{aligned}
& \mathrm{ET}_{\mathrm{a}}=\frac{\mathrm{LH}}{\rho_{\mathrm{w}} \cdot L_{\text {water }}} \\
& L_{\text {water }}=10^{-3} \cdot\left(2500.8-2.36 \cdot T+0.0016 \cdot T^{2}\right. \\
& \left.\quad-0.00006 \cdot T^{3}\right),
\end{aligned}
$$

where $\mathrm{ET}_{\mathrm{a}}$ is actual evapotranspiration $\left(\mathrm{m} \mathrm{s}^{-1}\right), \mathrm{LH}$ is latent heat flux $\left(\mathrm{W} \mathrm{m}^{-2}\right), \rho_{\mathrm{w}}$ is water density $\left(\mathrm{kg} \mathrm{m}^{-3}\right), L_{\text {water }}$ is latent heat of condensation of water in the temperature range from -25 to $40^{\circ} \mathrm{C}\left(\mathrm{J} \mathrm{kg}^{-1}\right)$, and $T$ is air temperature $\left({ }^{\circ} \mathrm{C}\right)$. 


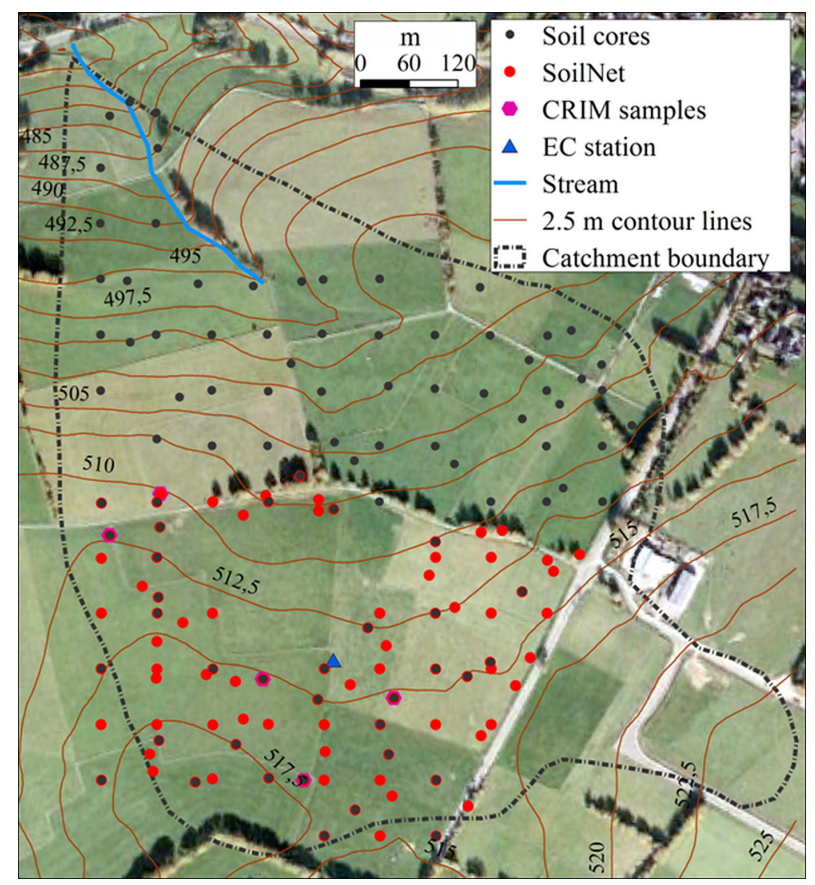

Figure 1. Map of the Rollesbroich catchment showing locations of the SoilNet sensor network, locations of the soil samples to determine soil physical and chemical properties, locations of the soil samples for site-specific calibration of the CRIM model, the location of the eddy covariance (EC) station, $2.5 \mathrm{~m}$ contour lines, and catchment boundary.

\subsection{Runoff}

Runoff was measured at the catchment outlet using a gauging station equipped with a combination of a V-notch weir for low flow measurements and a Parshall flume to measure normal to high flows. Runoff data of the two weir types were combined by using V-notch values for water levels below $5 \mathrm{~cm}$, Parshall flume values for water levels greater than $10 \mathrm{~cm}$ and the weighted mean of V-notch and Parshall flume values for water levels between 5 and $10 \mathrm{~cm}$, where the water levels refer to those of the V-notch weir.

\subsection{Soil water content}

Soil water content was measured at 87 SoilNet locations within the southern part of catchment (Fig. 1) using SPADE soil moisture sensors (Qu et al., 2013; Hübner et al., 2009). The SPADE sensors were installed at 5,20, and $50 \mathrm{~cm}$ depth. Two SPADE sensors were installed in parallel at each depth with a distance of $\sim 10 \mathrm{~cm}$ to increase the sensing volume and to allow examination of inconsistencies in sensor reading. The measurement frequency was $15 \mathrm{~min}$.

The SPADE sensor is a ring oscillator. The oscillator frequency is a function of the dielectric permittivity of the surrounding medium (Qu et al., 2013), which strongly depends on the water content of the soil because of the high permit-

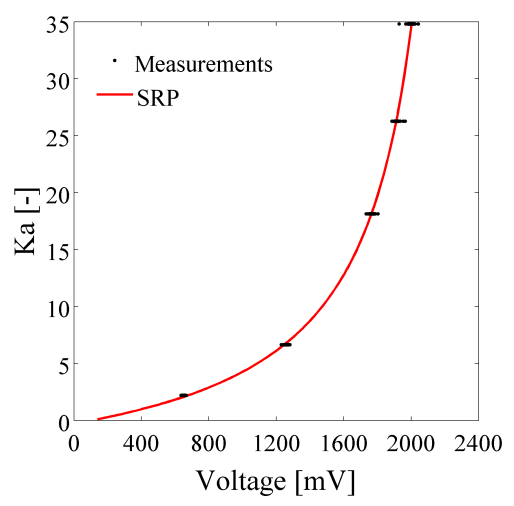

Figure 2. Sensor output of 60 SPADE sensors in five reference liquids ( $K_{a}$ refers to dielectric permittivity). The fitted "universal" calibration relationship (Eq. 3) is also presented.

tivity of water $\left(\varepsilon_{\mathrm{w}} \approx 80\right)$, as compared to mineral soil solids $\left(\varepsilon_{\mathrm{s}} \approx 2 \sim 9\right)$, and air $\left(\varepsilon_{\mathrm{a}} \approx 1\right)$. The temperature of the soil was also determined by the SPADE sensor using a digital thermometer (DS18B20) with an accuracy of $\pm 0.5^{\circ} \mathrm{C}$ in the range from -10 to $85^{\circ} \mathrm{C}$. The two-step calibration procedure suggested by Jones et al. (2005) was used to relate sensor reading to soil moisture. In a first step, reference liquids with a known dielectric permittivity were used to calibrate the following empirical model (Eq. 3) that relates sensor reading to apparent dielectric permittivity:

$K_{a}=\gamma+\frac{1}{\alpha+\beta / \nu}$,

where $K_{a}$ is the dielectric permittivity, $\alpha, \beta$, and $\gamma$ are the fitting parameters, and $v$ is sensor output (unit, V). Prior to installation, 60 SPADE sensors were calibrated in five reference liquids that covered a permittivity range from 2.2 to 34.8. The outputs for the 60 sensors as well as the fitted model are shown in Fig. 2. The root mean square error (RMSE) between known and predicted dielectric permittivity was 0.0188 , and the best fitting parameters of $\alpha, \beta$, and $\gamma$ were $-0.1502,0.3612$, and -0.1599 , respectively.

In a second step, a site-specific calibration between dielectric permittivity and soil water content was obtained using a complex refraction index model (CRIM, Eq. 4) as proposed by Birchak et al. (1974):

$\theta=\frac{K_{a}^{0.5}-(1-\eta) \cdot K_{\mathrm{solid}}^{0.5}-\eta \cdot K_{\mathrm{air}}^{0.5}}{K_{\mathrm{water}}^{0.5}-K_{\mathrm{air}}^{0.5}}$,

where $\eta$ is the porosity of the soil, $1-\eta$ is the solid fraction, $K_{a}$ is the permittivity of soil, and $K_{\text {water }}, K_{\text {solid }}$, and $K_{\text {air }}$ are the permittivity of water, solids, and air component of soil, respectively. In order to estimate the unknown value of $K_{\text {solid }}$ and to assess the accuracy of this relationship, 15 undisturbed samples (length $=7.7 \mathrm{~cm}$, diameter $=5 \mathrm{~cm}$ ) were taken from the two main soil types in 5,20 , and $50 \mathrm{~cm}$ 
Table 1. Parameters and the RMSE of the CRIM model for 5, 20, and $50 \mathrm{~cm}$ depth.

\begin{tabular}{lrrr}
\hline & $5 \mathrm{~cm}$ & $20 \mathrm{~cm}$ & $50 \mathrm{~cm}$ \\
\hline$K_{\text {water }}$ & 78.54 & 78.54 & 78.54 \\
$K_{\text {solid }}$ & 2.08 & 3.78 & 4.40 \\
$K_{\text {air }}$ & 1.00 & 1.00 & 1.00 \\
$\eta$ & 0.59 & 0.49 & 0.41 \\
RMSE & 0.028 & 0.025 & 0.022 \\
\hline
\end{tabular}

depth. These samples were first saturated with deionized water and then CS 640-L three-rod TDR probes with a length of $7.5 \mathrm{~cm}$ were inserted in the middle of the sample. These probes were connected to a TDR100 system (Campbell Scientific, Inc., Logan, USA) to determine the dielectric permittivity of the soil samples using a custom-made Matlab algorithm based on the travel time analysis algorithm of Heimovaara and Bouten (1990). Subsequently, the samples were dried and both weight and dielectric permittivity of each sample were determined in regular time intervals. After drying at room temperature, the remaining water was removed by oven-drying at $105^{\circ} \mathrm{C}$ for $24 \mathrm{~h}$ so that the dry bulk density, porosity, and the volumetric soil water content could be determined from the recorded weights.

The measured dielectric permittivity and soil water content and the fitted relationships are shown in Fig. 3. Because of the large difference in porosity at the three depths, the mean porosity at each depth was determined from the calibration samples and used to parameterize three different relationships. After fitting the solid permittivity for each depth, the performance of these calibration relationships was judged by the RMSE (Table 1). It was found that the three relationships performed well with a RMSE ranging from 0.022 to $0.028 \mathrm{~cm}^{3} \mathrm{~cm}^{-3}$.

As already briefly discussed in Qu et al. (2014), we found that sensor output showed artificially pronounced diurnal variations after the deployment of the sensor network. This behavior was attributed to a charging capacitor that affected the first reading of the SPADE sensor. If multiple sensor readings were made sequentially without turning off the sensor, the stability of the measurement considerably improved and the temperature dependence of the measurements disappeared ( $\mathrm{Qu}$ et al., 2014). To correct these temperature-dependent oscillations in sensor reading, the acquisition software of SoilNet was changed temporarily so that two measurements were saved from 5 September 2012 to 3 March 2013. After 3 March 2013, the software was updated again so that only the second more accurate measurement was saved. Figure 4 shows an example of the measured voltage for the first and second measurements and the soil temperature for a selected sensor (location $053,5 \mathrm{~cm}$ depth). It can be seen that the difference between the two measurements $(\Delta v)$ is strongly correlated with soil temperature and

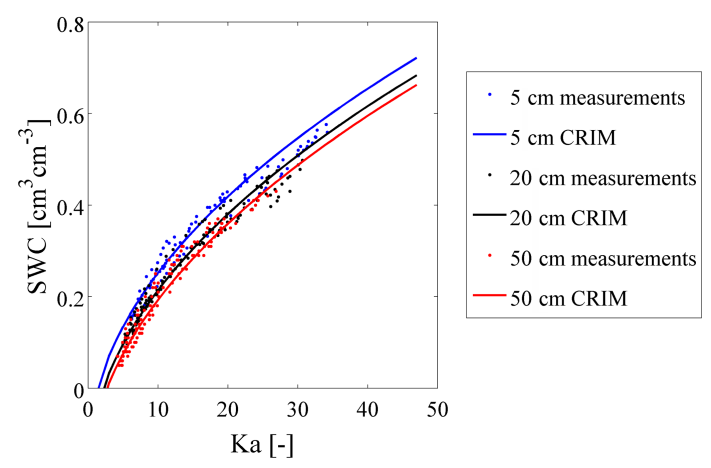

Figure 3. Relationship between dielectric permittivity and soil water content for the Rollesbroich test site and the derived $K_{a}-\theta$ models (CRIM).

could be fitted with an empirical second-order polynomial function with a RMSE of $5.18 \mathrm{mV}$ (Fig. 5). Such secondorder polynomial functions were obtained for all sensors individually and subsequently used to correct measurements made between April 2011 and September 2012. After the correction, measurements from the closely spaced sensors at a single measurement location agreed well with each other with a RMSE that varied from 0.010 to $0.035 \mathrm{~cm}^{3} \mathrm{~cm}^{-3}$. The uncorrected and corrected voltage as well as the associated soil water content of one representative sensor is plotted in Fig. 6. It is clear that the corrected measurements before September 2012 better match the expected soil water content after September 2012. On average, the corrected soil water content was $0.07 \mathrm{~cm}^{3} \mathrm{~cm}^{-3}$ lower than the uncorrected values. The plausibility of the corrected soil water content values is further supported by the fact that the increase in soil water content in the winter of 2012 disappeared after the temperature correction. The corrected soil water content is now relatively constant in winter and the maximum of the soil water content corresponds well with the porosity determined from the soil samples (both $0.59 \mathrm{~cm}^{3} \mathrm{~cm}^{-3}$ ).

\subsection{Soil physical properties}

Soil cores were taken at all locations where soil water content sensors were installed (length of $100 \mathrm{~cm}$, diameter of $8 \mathrm{~cm}$; Carl Hamm GmbH, Essen, Germany). Then, soil samples were taken from three pedological horizons $(0-10,10-$ 20, and 20-40 cm) within the soil cores (see Fig. 1), which resulted in a total of 282 soil samples. Sand, silt, and clay fractions were determined using a combination of wet sieving (sand fractions) and sedimentation (silt and clay fraction) following ISO-11277 (2009). Organic carbon (C) and total nitrogen $(\mathrm{N})$ content were determined by a combination of standard laboratory analyses (ISO-10694, 1995) and mid-infrared spectroscopy (MIRS) using partial least square regression (PLSR) (Bornemann et al., 2008). Mid-infrared spectra were recorded in diffuse reflectance mode by a Ten- 


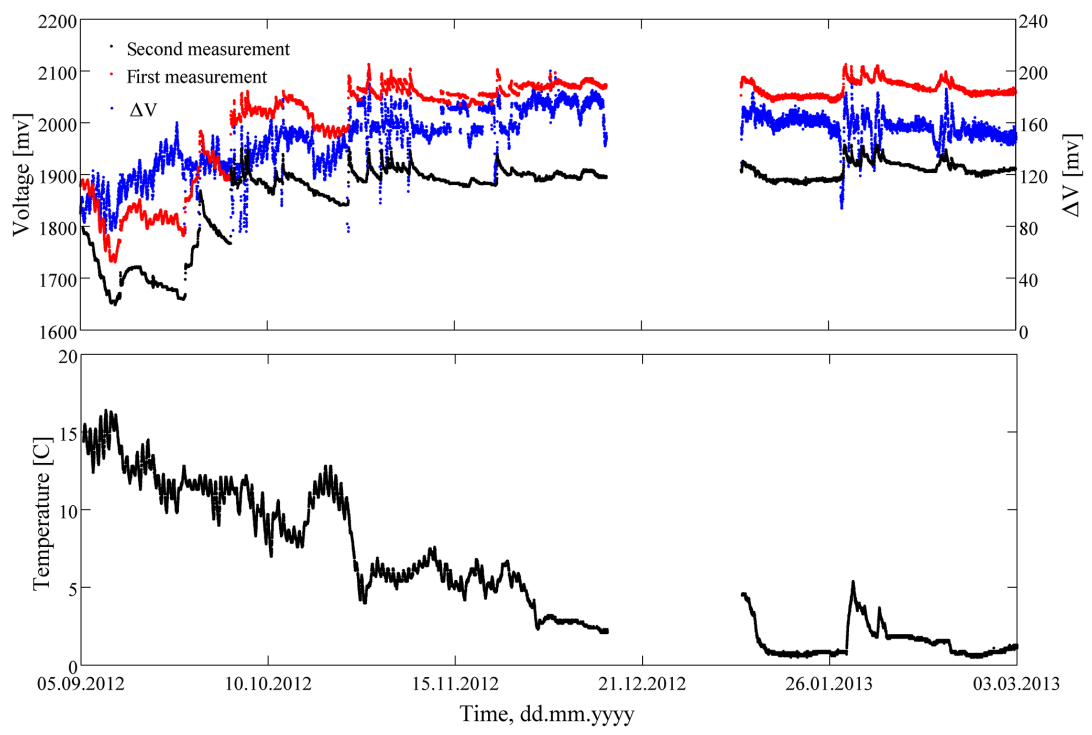

Figure 4. Time series of the first and second voltage measured after software update as well as the respective voltage differences $(\Delta V)$ and the associated temperatures.

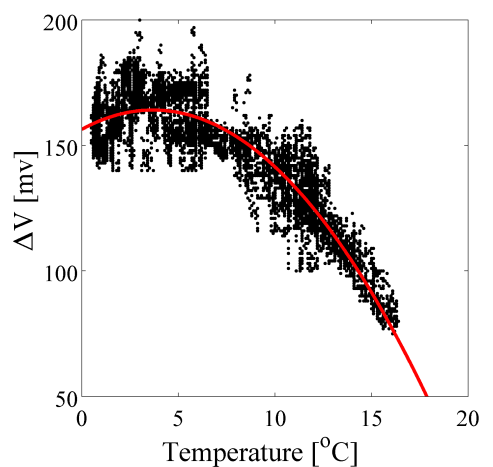

Figure 5. Second-order polynomial function fitted to the relationship between soil temperature and the difference between the first and second voltage measurements.

sor 27 (Bruker, Billerica, United States), extended with a high throughput device (HTS-XT) equipped with a liquid $\mathrm{N}_{2}$-cooled mercury-cadmium-telluride detector. The OPUS 6.0 software (Bruker) was used for spectrum analyses and evolution of prediction models for $\mathrm{C}$ and total N. Models were validated through cross- (leave-one-out) and test-set validation $(10 \%)$. Cross validation yielded coefficients of determination of 0.99 (for both $\mathrm{C}$ and total $\mathrm{N}$ ).

\subsection{Leaf area index}

The agricultural management of the different fields in the Rollesbroich catchment is very similar. Heterogeneity of the grass cover is mainly caused by different mowing times, which typically vary only by a few days. Therefore, we assume that the grass cover is homogeneous on the long-term in the Rollesbroich catchment. The effective leaf area in$\operatorname{dex}\left(\mathrm{LAI}_{\mathrm{eff}}\right)$ that contributes to actual evapotranspiration was computed from grass height, $h$, using the following equations (Allen et al., 2006; Rochette et al., 1991):

$\mathrm{LAI}=24 \cdot h$,

$\mathrm{LAI}_{\mathrm{eff}}=\frac{\mathrm{LAI}}{0.3 \cdot \mathrm{LAI}+1.2}$.

Average grass height in the Rollesbroich catchment was determined weekly by measuring grass height at five representative locations in the catchment.

Time series of LAI were also derived from RapidEye images using the normalized difference vegetation index (NDVI) approach (Myneni et al., 1997). The NDVI is calculated from infrared (NIR) and red-edge spectral bands. The NDVI of a plant with high LAI has a high ratio between NIR and red reflectance that can be detected by RapidEye. The LAI was computed from the NDVI values using a radiative transfer model (Myneni et al., 1997). Detailed information about the procedure can be found in Ali et al. (2013).

\section{Data management and quality control}

The distributed spatial data infrastructure TEODOOR (http: //www.tereno.net) was developed to handle, describe, exchange, and publish all monitored environmental data of the TERENO project (Kunkel et al., 2013). Each institution hosting an observatory maintains its local data infrastructure. The observatories are connected via OGC-compliant web services, while the TERENO Data Discovery Portal (DDP) as a central application enables data searching, visualization and 

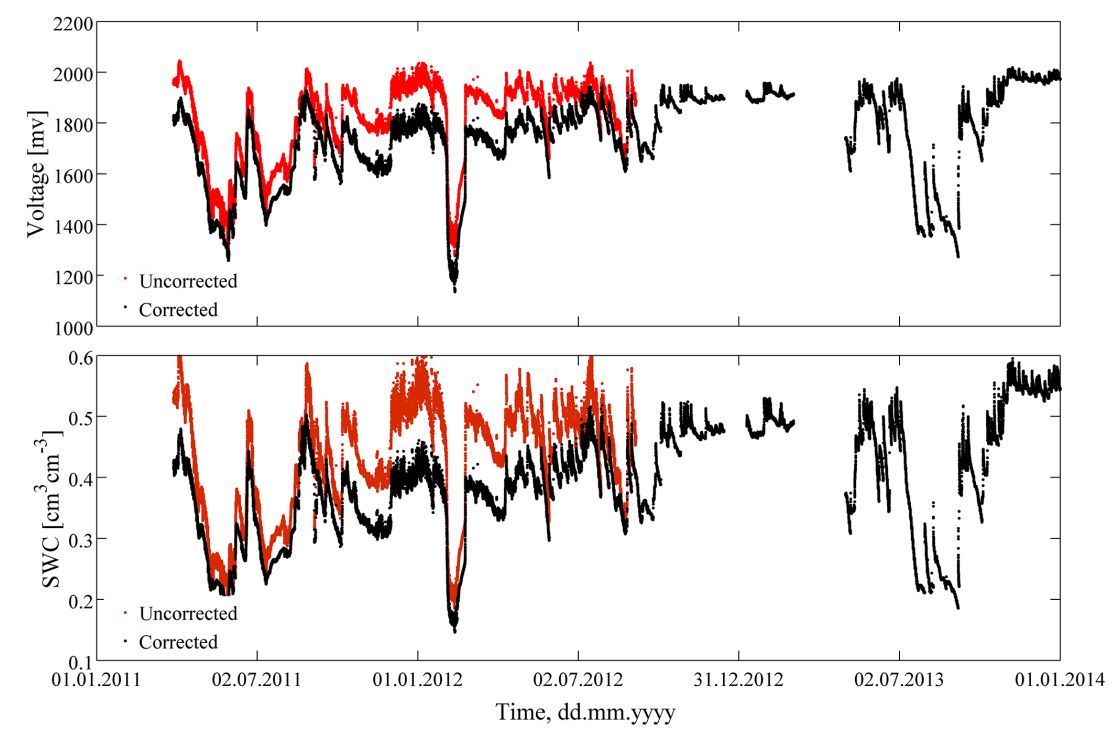

Figure 6. Time series of the uncorrected (red) and corrected (black) voltage and soil water content (SWC) measurements of one representative sensor.

download. According to the TERENO data policy it is obligate that each data set is described by standardized metadata elements, like ISO19115, OGC SensorML, or NetCDF's CF Conventions.

The observation data sets are processed and assessed within TEODOOR in three different ways (for details see Devaraju et al., 2015). In the first data processing type, the imported data undergo automated quality checks (e.g., minimum/maximum thresholds) and subsequently are published after visual inspection by experts. For example, data from weather stations and river gauges are processed in this way. Secondly, more complex data can be externally processed and assessed by the principal investigators and subsequently imported into TEODOOR, e.g., EC data. The third data processing type also involves automatic data import, but in this case the data quality assessment is executed using an external evaluation method developed by the responsible scientist, e.g., wireless sensor network data. Subsequently, the flagging information is updated by TEODOOR after the quality assessment has been completed.

Characterization of data quality is done by three descriptors, which are stored together with each observation: data uncertainty, data processing levels, and data quality flags. The observed data values remain unchanged in any case. Data uncertainty arises from the observation process itself and is mainly determined by the accuracy of the sensors used. Data processing levels indicate the status of data handling. For instance, (unpublished) raw data are termed "level 1 " and "level 2" refers to data subjected to quality control, whereas the higher levels refer to derived data products. The flagging scheme consists of two tiers: the first tier includes generic flags, e.g., "good", "unevaluated", "suspicious", or "bad". The second tier is use-case-specific and indicates ei- ther the result of individual quality tests, e.g., failed gradient checks, or background events affecting data values, e.g., icing events. In the following section, we present in more detail how data were checked for plausibility to derive the data sets used in this study.

\subsection{Meteorological data and latent heat flux}

Meteorological data were checked for quality by a multi-step quality control including the use of diagnostic information provided by the instruments, the application of site specific plausibility limits, visual inspections of the data series, and cross-checks with data from the nearby backup weather station. The quality control of the latent heat flux was in accordance with the standardized method for the processing and quality assessment of EC data as suggested by Mauder et al. (2013). This scheme includes site-specific plausibility limits and the application of a spike removal algorithm based on median absolute deviation of raw measurements. Processed half-hourly fluxes and statistics were checked using three different flags (high, moderate, and low) based on tests of integral turbulence and stationarity (Foken and Wichura, 1996). As a result of this quality check, $48.5 \%$ of all possible 30 min observations of latent heat flux were marked as goodquality data, $12.2 \%$ were marked as moderate quality, $35.4 \%$ were marked as low-quality data $(35.4 \%)$, while $3.9 \%$ were marked as missing data because of power failure and sensor maintenance. In this study, only data of high and moderate quality were used. A more detailed description of the treatment of EC data can be found elsewhere (Gebler et al., 2015; Post et al., 2015). 


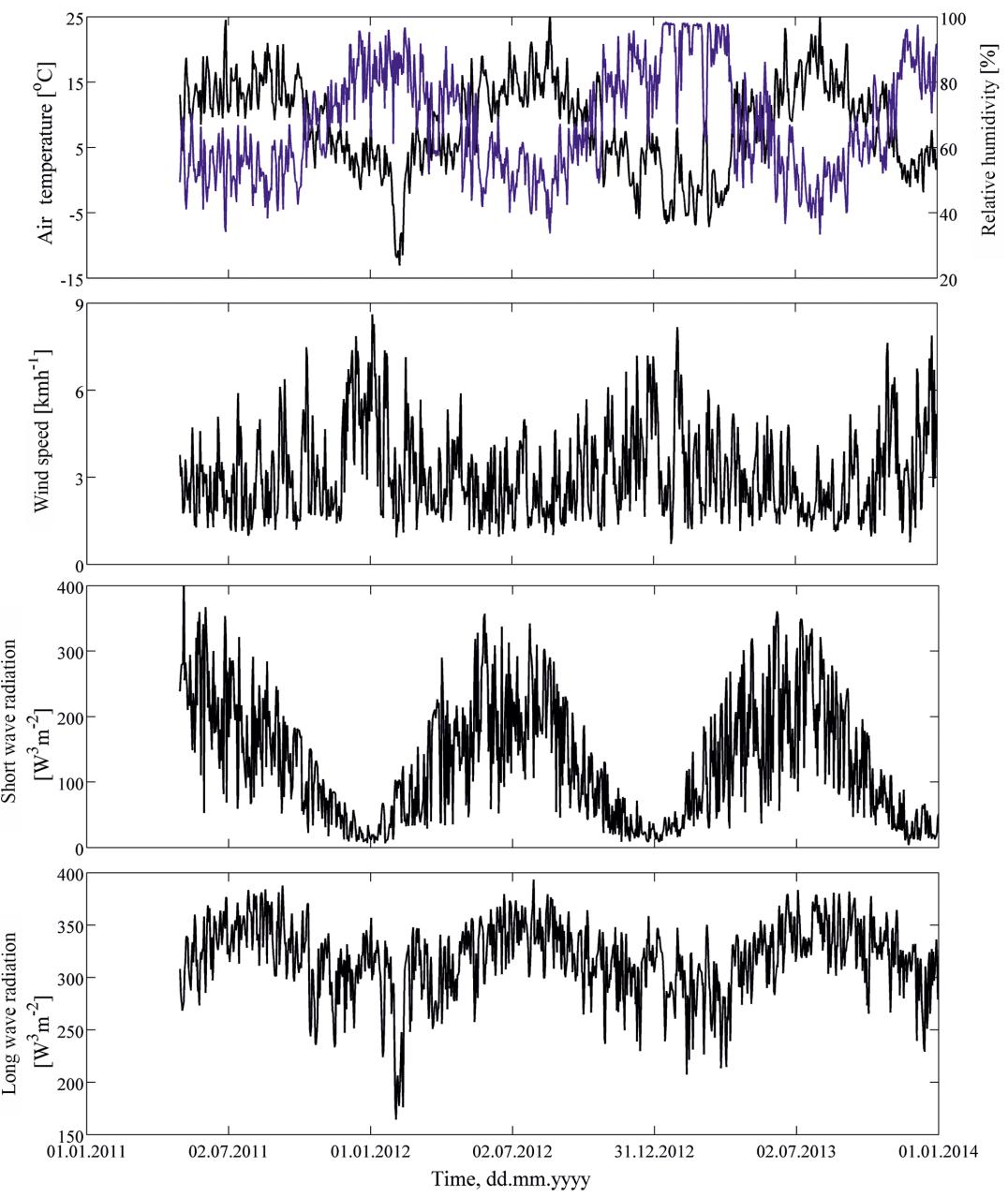

Figure 7. Daily averages of air temperature, relative humidity, wind speed, and incoming short- and long-wave radiation measured at the eddy covariance station from 1 May 2011 to 31 December 2013.

\subsection{Runoff}

As a first quality check, time series of the V-notch weir and a Parshall flume were compared for consistency. In addition, both runoff time series were visually inspected for inexplicable outliers (e.g., runoff peak without preceding rainfall event) and sensor failures. As outlined above, unreliable data were identified and appropriate flags were set.

\subsection{Soil water content}

Measurements of soil moisture outside the physical plausibility range ( 0.05 to $0.85 \mathrm{~cm}^{3} \mathrm{~cm}^{-3}$ ) were identified and flagged (please note that we used a conservative upper limit that can also be used for organic soils). Subsequently, unreliable measurements were identified by analyzing the first derivative of the soil water content time series. In case an increase larger than 2 times the standard deviations of the preceding $24 \mathrm{~h}$ was observed, this measurement was flagged as an unreliable measurement. In addition, the whole data set was visu- ally inspected to verify the results of the automatic flagging procedures.

\section{Data sets}

\subsection{Hydrometeorological data}

Temporal dynamics of the most important meteorological data (i.e., air temperature, air humidity, radiation components, wind speed, precipitation, actual evapotranspiration, and runoff) and water balance components (i.e., precipitation, actual evapotranspiration, runoff, and soil water content) from 1 May 2011 to 31 December 2013 are plotted in Figs. 7 and 8 . The air temperature, relative humidity, shortwave radiation, and evapotranspiration showed a clear annual pattern. The highest runoff amounts occurred during the winter seasons due to high precipitation amounts and low evapotranspiration rates, as well as overland flow due to saturation excess (Fig. 8). Generally, soil water content showed a strong dependence on precipitation events especially at 5 and $20 \mathrm{~cm}$ 
Table 2. Descriptive statistics of soil properties determined from 273 soil samples taken in the Rollesbroich catchment.

\begin{tabular}{llrrrrrr}
\hline & & $\begin{array}{r}\text { Clay } \\
\%\end{array}$ & $\begin{array}{r}\text { Sand } \\
\%\end{array}$ & $\begin{array}{r}\text { Silt } \\
\%\end{array}$ & $\begin{array}{r}\text { Bulk } \\
\text { density } \\
\left(\mathrm{g} \mathrm{cm}^{-3}\right)\end{array}$ & $\begin{array}{r}\text { Carbon } \\
\text { content } \\
\left(\mathrm{g} \mathrm{kg}^{-1}\right)\end{array}$ & $\begin{array}{r}\text { Porosity } \\
\left(\mathrm{cm}^{3} \mathrm{~cm}^{-3}\right)\end{array}$ \\
\hline $5 \mathrm{~cm}$ & mean & 18.99 & 19.90 & 61.10 & 0.94 & 54.47 & 0.65 \\
& SD & 2.00 & 3.82 & 3.79 & 0.12 & 15.82 & 0.05 \\
\hline \multirow{2}{*}{$20 \mathrm{~cm}$} & mean & 18.03 & 20.76 & 61.20 & 1.28 & 34.08 & 0.52 \\
& SD & 1.99 & 4.03 & 3.46 & 0.15 & 16.84 & 0.05 \\
\hline \multirow{2}{*}{$50 \mathrm{~cm}$} & mean & 16.50 & 22.00 & 61.50 & 1.52 & 11.22 & 0.43 \\
& SD & 2.40 & 5.68 & 4.53 & 0.16 & 6.01 & 0.06 \\
\hline
\end{tabular}

Table 3. ANOVA results of LAI determination with grass height and RapidEye from May to December 2011.

\begin{tabular}{lrrrrrr}
\hline Source of variation & SS & $\mathrm{d} f$ & $\mathrm{MS}$ & $F$ & $P$ value & $F$ critical \\
\hline Variability between group & 0.311 & 1 & 0.311 & 0.717 & 0.411 & 2.145 \\
Variability within group & 6.074 & 14 & 0.434 & & & \\
Total & 6.385 & 15 & & & & \\
\hline
\end{tabular}

depth. Quick increases in soil water content can be observed after rainfall events, which were followed by a slow recession during periods without precipitation. A detailed analysis of the spatial variability of the soil moisture has been presented by Qu et al. (2014).

In addition, there seems to be a rising trend in the soil moisture signal in the first year, which might be due to slow soil recompaction after installation (see, e.g., Poltoradnev et al., 2014) or a temporal drift in the electronics of the SPADE sensors. Unfortunately, the exact reasons are unclear. The trend in the average soil moisture content could be corrected using independent cosmic-ray soil moisture measurements (see Baatz et al., 2014), but this is not possible for the individual sensors. Since any correction of individual sensors is going to be subjective because of a lack of appropriate reference measurements, we have decided to refrain from doing further data corrections at this stage. We are convinced that the data are still useful despite possible (minor) sensor drifts, as also demonstrated by a range of recent publications relying on this data (e.g., Qu et al., 2014, 2015; Baatz et al., 2014, 2015).

\subsection{Water balance closure}

The water balance can be written as

$P=R+\mathrm{ET}_{\mathrm{a}}+\Delta S$,

where $P$ is precipitation, $R$ is runoff, $\mathrm{ET}_{\mathrm{a}}$ is actual evapotranspiration, and $\Delta S$ is the storage term. Because of the relatively low hydraulic conductivity $\left(10^{-9}\right.$ to $\left.10^{-7} \mathrm{~m} \mathrm{~s}^{-1}\right)$ of the aquifer bedrock (HK100, 2009), we neglected deep percolation. Mean average annual precipitation was partitioned into about $57 \%$ actual evapotranspiration and $50 \%$ runoff.
The residual of the balance was within $7 \%$ of precipitation for the whole time period as shown in Fig. 8. This residual is related to measurement uncertainty and soil water storage depletion. As presented by Graf et al. (2014), soil water storage can be derived from the measured soil water content, $\theta$, as follows:

$$
S(t)=\int \theta(x, y, z, t) \mathrm{d} x \mathrm{~d} y \mathrm{~d} z \mathrm{~d} t \approx \sum_{i=1}^{N} c_{i} \theta(i, t)+\varepsilon,
$$

where $t$ is time, $z$ is depth, the integral refers to the $3-\mathrm{D}$ domain as defined by the catchment boundary. The discrete version of storage is expressed by the right-hand side of the equation, where $i$ is the number of sensors, and $c_{i}$ is the empirical coefficient representing the 3-D domain which is well represented by the sensor. The residual of $\varepsilon$ is the storage affected by vegetation or groundwater and not represented well by the sensor. The changes in $\Delta S$ are expected to correspond well with the residual of the major water budget component, $P$-ET $\mathrm{a}_{\mathrm{a}}-R$ (Eq. 7). Thus, the time derivative of soil water storage should be linearly related to this residual, although measurement errors within the other water balance components and the unaccounted storage terms (e.g., vegetation storage) will deteriorate this relation. Our results show that there is a linear relationship between the derivative of soil water content and the water balance residual (Fig. 9). The $R^{2}$ is 0.60 , which means that $60 \%$ of the residual of the water balance is explained by soil water storage changes in the catchment.

\subsection{Soil physical properties}

The mean and standard deviation of sand, silt, and clay percentages, organic carbon content, and bulk density are shown 


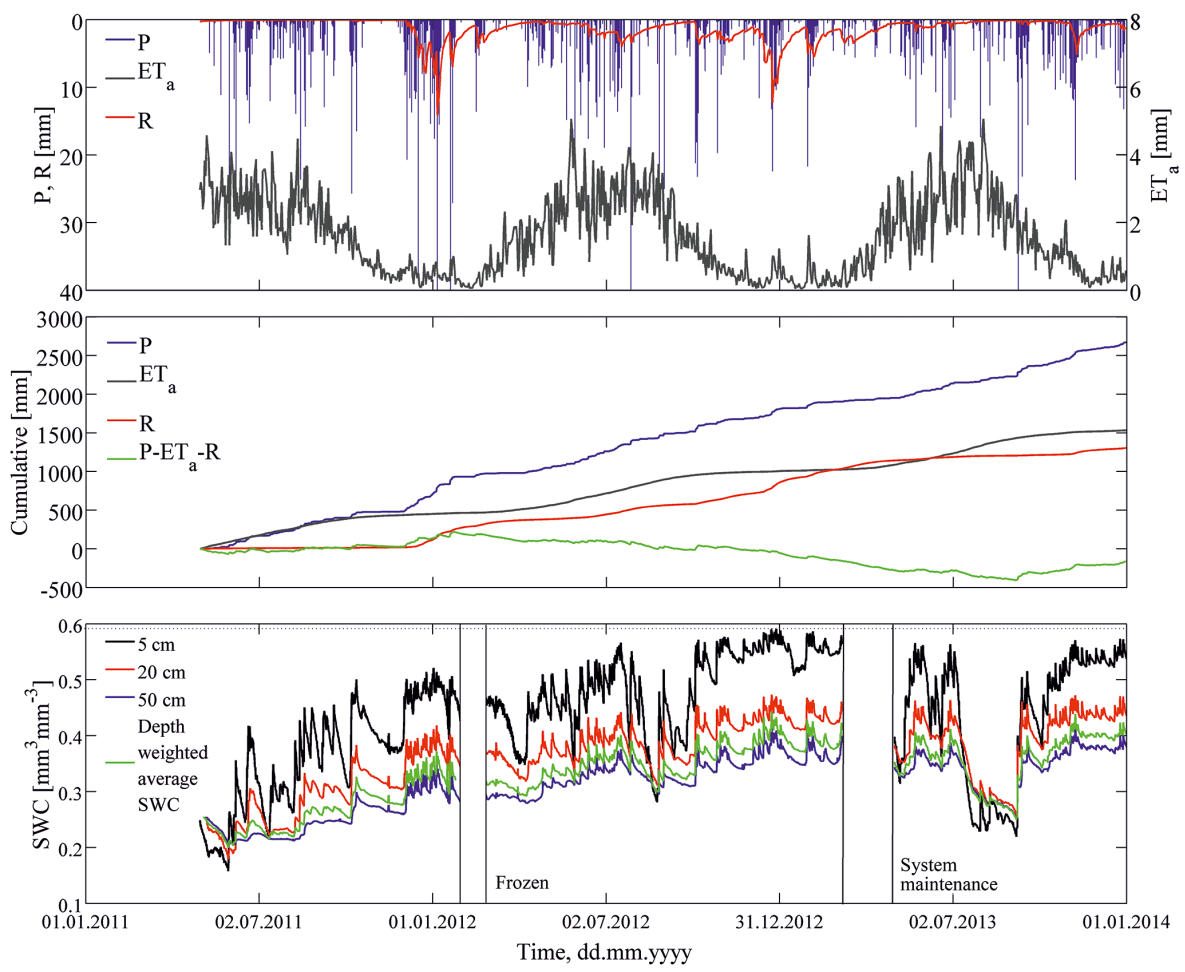

Figure 8. Daily and cumulative time series (1 May 2011 to 31 December 2013) of precipitation $(P)$, runoff $(R)$, actual evapotranspiration $\left(\mathrm{ET}_{\mathrm{a}}\right)$, and spatial mean soil water content (SWC) at three depths. The SWC data contains two major gaps due to frozen soil conditions and maintenance of the SoilNet system. The dashed line indicates the soil porosity determined from the soil samples $\left(0.59 \mathrm{~cm}^{3} \mathrm{~cm}^{-3}\right)$.

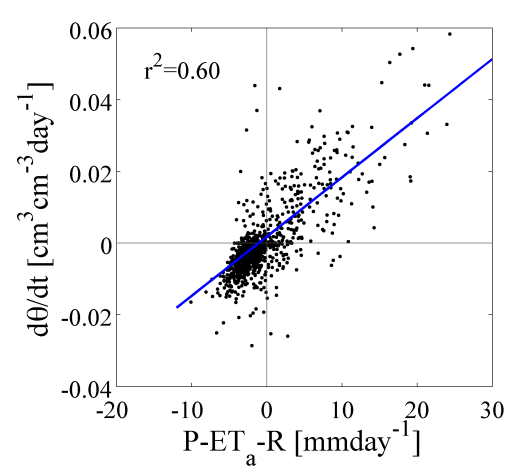

Figure 9. Time derivative of volumetric soil water content (average of all depth) vs. the water balance residual.

in Table 2. The bulk density ranged from 0.94 to $1.52 \mathrm{~g} \mathrm{~cm}^{-3}$ and generally increased with depth. Porosity ranged from 0.43 to $0.65 \mathrm{~cm}^{3} \mathrm{~cm}^{-3}$ and decreased with depth. The higher spatial variability of porosity of the subsoil is caused by the higher and more variable stone content at this depth. In addition, former agriculture land management activities reduced the spatial variability of porosity of the top soil (plough layer, 20 to $30 \mathrm{~cm}$ thick). The measured soil texture fractions and soil density were used to estimate the spatial distribution of soil hydraulic properties with the pedotransfer function Rosetta (Schaap et al., 2001). Figure 10 shows the spatial distribution of Mualem-van Genuchten (MvG) soil hydraulic parameters (van Genuchten, 1980) derived with Rosetta at $5 \mathrm{~cm}$ depth. Some soil hydraulic parameters show a distinct pattern. For instance, the MvG parameter $\alpha$ is generally larger in the northern part than in the southern part of the catchment. Such information is important for the investigation of controlling factors of spatial patterns of soil water content.

\subsection{Leaf area index}

The LAI derived from measured grass height agrees well with the LAI obtained from RapidEye images (Fig. 11). Both LAI time series showed a distinct annual pattern with the highest values during the summer time. We averaged the monthly LAI derived from measured grass height and an ANOVA was conducted to test whether there was a significant difference between the LAI obtained from grass height and RapidEye in the time period of May to December in 2011. The results of this ANOVA (Table 3) confirmed that there is no significant difference between the two methods to determine LAI. 

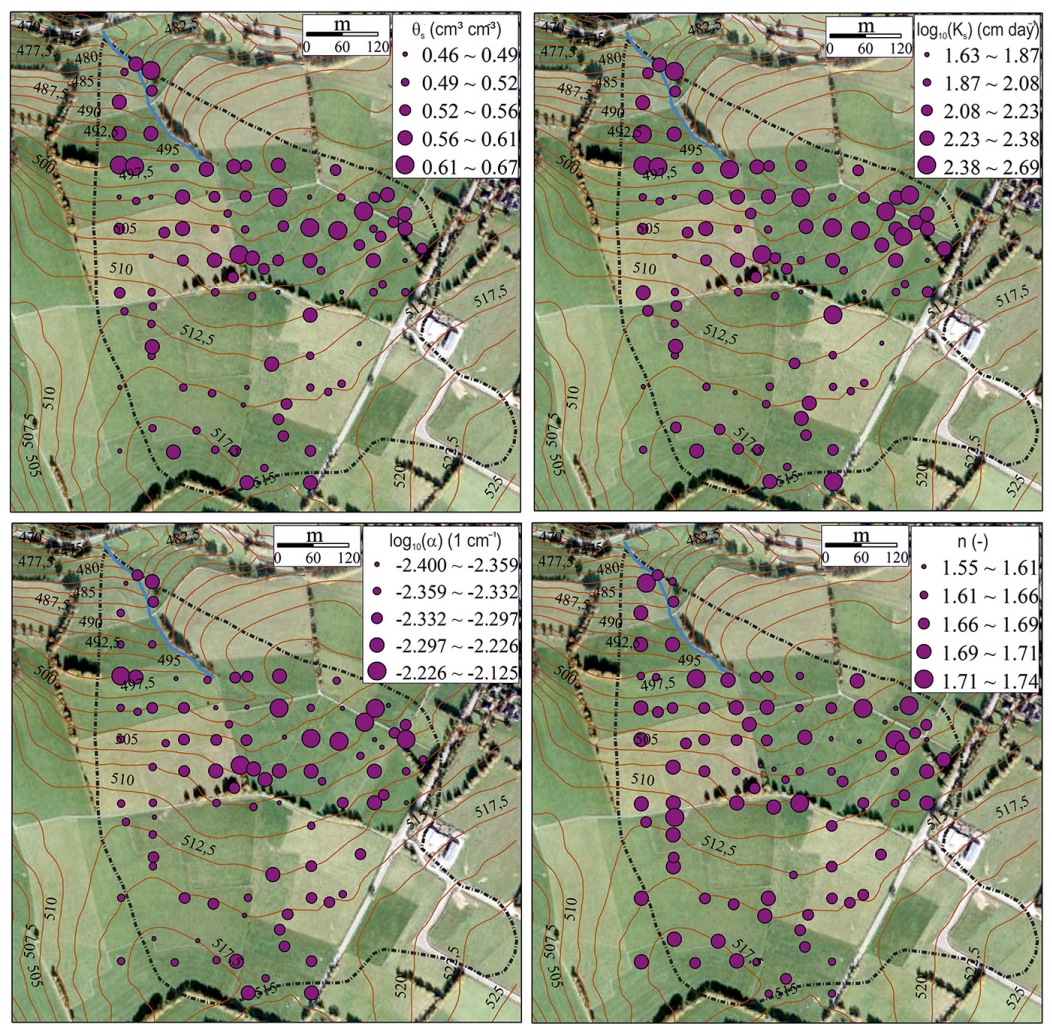

Figure 10. Spatial distribution of soil hydraulic properties $\left(\theta_{\mathrm{S}}, \log _{10}\left(K_{\mathrm{S}}\right), \log _{10}(\alpha)\right.$, and $\left.n\right)$ at $5 \mathrm{~cm}$ depth derived from soil information obtained from the soil cores taken in the Rollesbroich catchment.

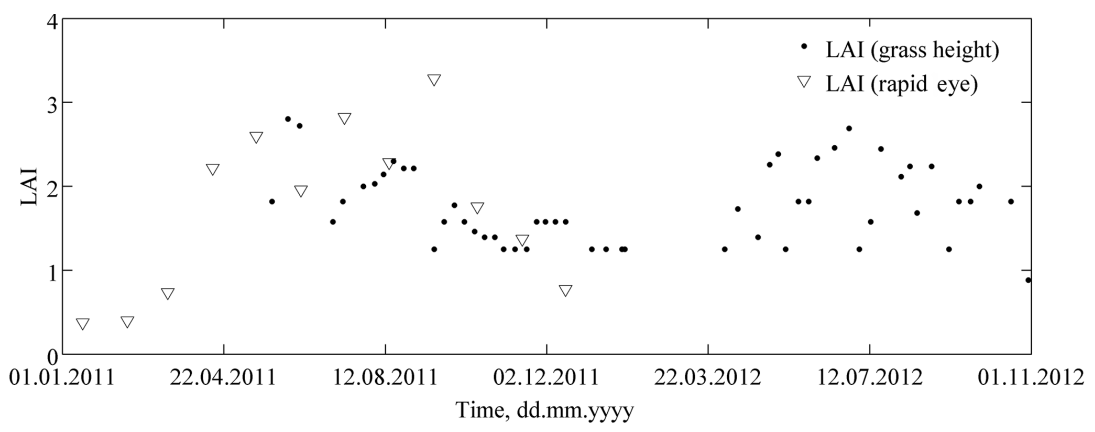

Figure 11. Time series of leaf area index (LAI) computed from measured grass height and extracted from the RapidEye images of the Rollesbroich catchment.

\section{Data availability}

We presented data from the intensively instrumented hydrological observatory Rollesbroich providing long-term hydrometeorological data with high spatial and temporal resolution. Our results showed that the catchment water balance is reasonably closed by the provided measurements and that $60 \%$ of the water balance residual could be related to soil water storage changes within the Rollesbroich catchment. In addition, important soil physical and chemical properties (e.g., hydraulic properties) have been reported in addition to catchment-scale information on vegetation. This comprehen- sive hydrological data set can be used for the calibration, validation and improvement of hydrological models, e.g., in hydrological model intercomparison projects (Breuer et al., 2009; Maxwell et al., 2014; Refsgaard, 1997; Smith et al., 2004) and for the calibration and validation of remote sensing data products (Bastiaanssen et al., 1998; Jackson et al., 2010; Le Hegarat-Mascle et al., 2002; Njoku et al., 2003). All the presented data and data from further monitoring stations located in the Rollesbroich catchment are freely available from the TERENO data portal (http://www.tereno.net). In addition, three persistent identifiers are associated with the data set described here: 
- climate/runoff/water quality station: doi:10.5880/TERENO.2016.001 (Bogena, 2016a)

- EC/climate station Rollesbroich: doi:10.5880/TERENO.2016.004 (Schmidt, 2016)

- SoilNet Rollesbroich: doi:10.5880/TERENO.2016.003 (Bogena, 2016b)

Please note that the NetCDF format is used, which is a standard format for data exchange. There is free conversion software available to convert the NetCDF data format in other data formats, e.g., at http://www.giss.nasa.gov/tools/ panoply/. In addition, an Excel file containing the basic soil information is available at the "SoilNet Rollesbroich" download site and two Excel files containing the LAI information presented in Fig. 11 are available at the "EC/Climate station Rollesbroich" download site.

Acknowledgements. We gratefully acknowledge the support of the SFB-TR32 "Pattern in Soil-Vegetation-Atmosphere Systems: Monitoring, Modeling and Data Assimilation" funded by the Deutsche Forschungsgemeinschaft (DFG), and TERENO funded by the Helmholtz Association. Martina Kettler and Daniel Dolfus are thanked for supporting the acquisition of vegetation information.

Edited by: N. Verhoest

Reviewed by: three anonymous referees

\section{References}

Ali, M., Montzka, C., Stadler, A., Menz, G., and Vereecken, H.: Estimation and validation of leaf area index time series for crops on $5 \mathrm{~m}$ scale from space, International Geosciences and Remote Sensing Symposium (IGARSS), Melbourne, Australia, 21-26 July 2013.

Albertson, J. D. and Kiely, G.: On the structure of soil moisture time series in the context of land surface models, J. Hydrol., 243, 101-119, 2001.

Allen, R. G., Pruitt, W. O., Wright, J. L., Howell, T. A., Ventura, F., Snyder, R., Itenfisu, D., Steduto, P., Berengena, J., Yrisarry, J. B., Smith, M., Pereira, L. S., Raes, D., Perrier, A., Alves, I., Walter, I., and Elliott, R.: A recommendation on standardized surface resistance for hourly calculation of reference eto by the fao56 penman-monteith method, Agr. Water Manage., 81, 1-22, 2006.

Baatz, R., Bogena, H., Hendricks Franssen, H.-J., Huisman, J. A., Wei, Q., Montzka, C., and Vereecken, H.: Calibration of a catchment scale cosmic-ray soil moisture network: A comparison of three different methods, J. Hydrol., 516, 231-244, 2014.

Baatz, R., Bogena, H., Hendricks Franssen, H.-J., Huisman, J. A., Montzka, C., and Vereecken, H.: An empirical vegetation correction for soil water content quantification using cosmic ray probes, Water Resour. Res., 51, 2030-2046, 2015.
Bastiaanssen, W. G. M., Pelgrum, H., Wang, J., Ma, Y., Moreno, J. F., Roerink, G. J., and van der Wal, T.: A remote sensing surface energy balance algorithm for land (sebal) - 2. Validation, J. Hydrol., 212, 213-229, 1998.

Betts, A. K., Ball, J. H., Beljaars, A. C. M., Miller, M. J., and Viterbo, P. A.: The land surface-atmosphere interaction: A review based on observational and global modeling perspectives, J. Geophys. Res.-Atmos., 101, 7209-7225, 1996.

Birchak, J. R., Gardner, C. G., Hipp, J. E., and Victor, J. M.: High dielectric constant microwave probes for sensing soil moisture, P. IEEE, 62, 93-98, 1974.

Bloschl, G. and Sivapalan, M.: Scale issues in hydrological modeling - a review, Hydrol. Process., 9, 251-290, 1995.

Bogena, H.: TERENO (Eifel-Rur), Climate/Runoff/Water Quality station Rollesbroich, Germany, GFZ Data Services, doi:10.5880/TERENO.2016.001, 2016a.

Bogena, H.: TERENO (Eifel-Rur), SoilNet Rollesbroich, Germany, GFZ Data Services, doi:10.5880/TERENO.2016.003, $2016 \mathrm{~b}$.

Bogena, H., Kunkel, R., Pütz, T., Vereecken, H., Krüger, E., Zacharias, S., Dietrich, P., Wollschläger, U., Kunstmann, H., Papen, H., Schmid, H. P., and Munch, J. C.: Tereno - long-term monitoring network for terrestrial research, Hydrol. Wasserbewirts., 56, 138-143, 2012.

Bogena, H. R., Bol, R., Borchard, N., Brueggemann, N., Diekkrueger, B., Druee, C., Groh, J., Gottselig, N., Huisman, J. A., Luecke, A., Missong, A., Neuwirth, B., Puetz, T., Schmidt, M., Stockinger, M., Tappe, W., Weihermueller, L., Wiekenkamp, I., and Vereecken, H.: A terrestrial observatory approach to the integrated investigation of the effects of deforestation on water, energy, and matter fluxes, Science China-Earth Sciences, 58, 6175, 2015.

Bornemann, L., Welp, G., Brodowski, S., Rodionov, A., and Amelung, W.: Rapid assessment of black carbon in soil organic matter using mid-infrared spectroscopy, Org. Geochem., 39, 1537-1544, 2008.

Breuer, L., Huisman, J. A., Willems, P., Bormann, H., Bronstert, A., Croke, B. F. W., Frede, H. G., Graeff, T., Hubrechts, L., Jakeman, A. J., Kite, G., Lanini, J., Leavesley, G., Lettenmaier, D. P., Lindstroem, G., Seibert, J., Sivapalan, M., and Viney, N. R.: Assessing the impact of land use change on hydrology by ensemble modeling (luchem). I: Model intercomparison with current land use, Adv. Water Resour., 32, 129-146, 2009.

Cosh, M. H., Ochsner, T. E., McKee, L., Dong, J., Basara, J. B., Evett, S. R., Hatch, C. E., Small, E. E., Steele-Dunne, S. C., Zreda, M., and Sayde, C.: The Soil Moisture Active Passive Marena, Oklahoma, In Situ Sensor Testbed (SMAP-MOISST): Testbed Design and Evaluation of In Situ Sensors, Vadose Zone J., 15, doi:10.2136/vzj2015.09.0122, 2016.

Crow, W. T., Ryu, D., and Famiglietti, J. S.: Upscaling of field-scale soil moisture measurements using distributed land surface modeling, Adv. Water Resour., 28, 1-14, 2005.

Devaraju, A., Jirka, S., Kunkel, R., and Sorg, J.: Q-SOS - A Sensor Observation Service for Accessing Quality Descriptions of Environmental Data, ISPRS Int. J. Geo-Inf., 4, 1346-1365, 2015.

Dirnbock, T., Dullinger, S., and Grabherr, G.: A regional impact assessment of climate and land-use change on alpine vegetation, J. Biogeogr., 30, 401-417, 2003. 
Evett, S. R., Schwartz, R. C., Casanova, J. J., and Heng, L. K.: Soil water sensing for water balance, Agr. Water Manage., 104, 1-9, 2012.

Flerchinger, G. N. and Cooley, K. R.: A ten-year water balance of a mountainous semi-arid watershed, J. Hydrol., 237, 86-99, 2000.

Foken, T. and Wichura, B.: Tools for quality assessment of surfacebased flux measurements, Agr. Forest Meteorol., 78, 83-105, 1996.

Foley, J. A., Levis, S., Prentice, I. C., Pollard, D., and Thompson, S. L.: Coupling dynamic models of climate and vegetation, Glob. Change Biol., 4, 561-579, 1998.

Gebler, S., Hendricks Franssen, H.-J., Pütz, T., Post, H., Schmidt, M., and Vereecken, H.: Actual evapotranspiration and precipitation measured by lysimeters: a comparison with eddy covariance and tipping bucket, Hydrol. Earth Syst. Sci., 19, 2145-2161, doi:10.5194/hess-19-2145-2015, 2015.

Graf, A., Bogena, H. R., Druee, C., Hardelauf, H., Puetz, T., Heinemann, G., and Vereecken, H.: Spatiotemporal relations between water budget components and soil water content in a forested tributary catchment, Water Resour. Res., 50, 4837-4857, 2014.

Guo, L. and Lin, H.: Critical Zone Research and Observatories: Current Status and Future Perspectives, Vadose Zone J., 15, doi:10.2136/vzj2016.06.0050, 2016.

Heimovaara, T. J. and Bouten, W.: A computer-controlled 36channel time domain reflectometry system for monitoring soilwater contents, Water Resour. Res., 26, 2311-2316, 1990.

Hinzman, L. D., Bettez, N. D., Bolton, W. R., Chapin, F. S., Dyurgerov, M. B., Fastie, C. L., Griffith, B., Hollister, R. D., Hope, A., Huntington, H. P., Jensen, A. M., Jia, G. J., Jorgenson, T., Kane, D. L., Klein, D. R., Kofinas, G., Lynch, A. H., Lloyd, A. H., McGuire, A. D., Nelson, F. E., Oechel, W. C., Osterkamp, T. E., Racine, C. H., Romanovsky, V. E., Stone, R. S., Stow, D. A., Sturm, M., Tweedie, C. E., Vourlitis, G. L., Walker, M. D., Walker, D. A., Webber, P. J., Welker, J. M., Winker, K., and Yoshikawa, K.: Evidence and implications of recent climate change in northern alaska and other arctic regions, Climatic Change, 72, 251-298, 2005.

HK100: Hydrogeological map of north Rhine-Westphalia (1:100000), Geological Survey, North Rhine-Westphalia, Krefeld, Germany, 2009.

Hübner, C., Cardell-Oliver, R., Becker, R., Spohrer, K., Jotter, K., and Wagenknecht, T.: Wireless soil moisture sensor networks for environmental monitoring and vineyard irrigation, Helsinki University of Technology, No. 1, 408-415, 2009.

Huntington, T. G.: Evidence for intensification of the global water cycle: Review and synthesis, J. Hydrol., 319, 83-95, 2006.

ISO-10694: Soil quality - determination of organic and total carbon after dry combustion (elemental analysis), Beuth, Berlin, 1995.

ISO-11277: Soil quality - determination of particle size distribution in mineral soil material - method by sieving and sedimentation, Beuth, Berlin, 2009.

Jackson, T. J., Cosh, M. H., Bindlish, R., Starks, P. J., Bosch, D. D., Seyfried, M., Goodrich, D. C., Moran, M. S., and Du, J.: Validation of advanced microwave scanning radiometer soil moisture products, IEEE T. Geosci. Remote Sens., 48, 4256-4272, 2010.

Jaeger, E. B. and Seneviratne, S. I.: Impact of soil moistureatmosphere coupling on european climate extremes and trends in a regional climate model, Clim. Dynam., 36, 1919-1939, 2011.
Jones, S. B., Blonquist, J. M., Robinson, D. A., Rasmussen, V. P., and Or, D.: Standardizing characterization of electromagnetic water content sensors: Part 1. Methodology, Vadose Zone J., 4, 1048-1058, 2005.

Kampf, S. K. and Burges, S. J.: Quantifying the water balance in a planar hillslope plot: Effects of measurement errors on flow prediction, J. Hydrol., 380, 191-202, 2010.

Kunkel, R., Sorg, J., Eckardt, R., Kolditz, O., Rink, K., and Vereecken, H.: Teodoor: A distributed geodata infrastructure for terrestrial observation data, Environmental Earth Sciences, 69, 507-521, 2013.

Le Hegarat-Mascle, S., Zribi, M., Alem, F., Weisse, A., and Loumagne, C.: Soil moisture estimation from ers/sar data: Toward an operational methodology, IEEE T. Geosci. Remote Sens., 40, 2647-2658, 2002.

Mauder, M. and Foken, Th.: Documentation and Instruction Manual of the Eddy-Covariance Software Package TK3. Arbeitsergebnisse, Universität Bayreuth, Abteilung Mikrometeorologie 46, Bayreuth, available at: https://epub.uni-bayreuth.de/id/eprint/ 342 (last access: 14 October 2016), 2011.

Mauder, M., Cuntz, M., Druee, C., Graf, A., Rebmann, C., Schmid, H. P., Schmidt, M., and Steinbrecher, R.: A strategy for quality and uncertainty assessment of long-term eddy-covariance measurements, Agr. Forest Meteorol., 169, 122-135, 2013.

Maxwell, R. M., Putti, M., Meyerhoff, S., Delfs, J.-O., Ferguson, I. M., Ivanov, V., Kim, J., Kolditz, O., Kollet, S. J., Kumar, M., Lopez, S., Niu, J., Paniconi, C., Park, Y.-J., Phanikumar, M. S., Shen, C., Sudicky, E. A., and Sulis, M., 2014, Surface-subsurface model intercomparison: A first set of benchmark results to diagnose integrated hydrology and feedbacks, Water Resour. Res., 50, 1531-1549, 2014.

Moncrieff, J. B., Massheder, J. M., deBruin, H., Elbers, J., Friborg, T., Heusinkveld, B., Kabat, P., Scott, S., Soegaard, H., and Verhoef, A.: A system to measure surface fluxes of momentum, sensible heat, water vapour and carbon dioxide, J. Hydrol., 189, 589-611, 1997.

Myneni, R. B., Nemani, R. R., and Running, S. W.: Estimation of global leaf area index and absorbed par using radiative transfer models, IEEE T. Geosci. Remote Sens., 35, 1380-1393, 1997.

Njoku, E. G., Jackson, T. J., Lakshmi, V., Chan, T. K., and Nghiem, S. V.: Soil moisture retrieval from amsr-e, IEEE T. Geosci. Remote Sens., 41, 215-229, 2003.

Poltoradnev, M., Ingwersen, J., and Streck, T.: Calibration and Application of Aquaflex TDT Soil Water Probes to Measure the Soil Water Dynamics of Agricultural Topsoil in Southwest Germany, J. Irrig. Drain. E.-ASCE, 141, doi:10.1061/(ASCE)IR.19434774.0000838, 2014.

Post, H., Hendricks Franssen, H. J., Graf, A., Schmidt, M., and Vereecken, $\mathrm{H}$.: Uncertainty analysis of eddy covariance $\mathrm{CO}_{2}$ flux measurements for different EC tower distances using an extended two-tower approach, Biogeosciences, 12, 1205-1221, doi:10.5194/bg-12-1205-2015, 2015.

Qu, W., Bogena, H. R., Huisman, J. A., and Vereecken, H.: Calibration of a novel low-cost soil water content sensor based on a ring oscillator, Vadose Zone J., 12, 2013.

Qu, W., Bogena, H. R., Huisman, J. A., Martinez, G., Pachepsky, Y., and Vereecken, H.: Effects of soil hydraulic properties on the spatial variability of soil water content: Evidence from sensor network data and inverse modeling, Vadose Zone J., 13, 2014. 
Qu, W., Bogena, H. R., Huisman, J. A., Vanderborght, J., Schuh, M., Priesack, E., and Vereecken, H.: Predicting sub-grid variability of soil water content from basic soil information, Geophys. Res. Lett., 42, 789-796, 2015.

Refsgaard, J. C.: Parameterisation, calibration and validation of distributed hydrological models, J. Hydrol., 198, 69-97, 1997.

Robinson, D. A., Campbell, C. S., Hopmans, J. W., Hornbuckle, B. K., Jones, S. B., Knight, R., Ogden, F., Selker, J., and Wendroth, O.: Soil moisture measurement for ecological and hydrological watershed-scale observatories: A review, Vadose Zone J., 7, 358389, 2008

Rochette, P., Pattey, E., Desjardins, R. L., Dwyer, L. M., Stewart, D. W., and Dube, P. A.: Estimation of maize (zea-mays-1) canopy conductance by scaling up leaf stomatal conductance, Agr. Forest Meteorol., 54, 241-261, 1991.

Rötzer, K., Montzka, C., Bogena, H., Wagner, W., Kidd, R., and Vereecken, H.: Catchment scale validation of SMOS and ASCAT soil moisture products using hydrological modelling and temporal stability analysis, J. Hydrol., 519, 934-946, 2014.

Schaap, M. G., Leij, F. J., and van Genuchten, M. T.: Rosetta: A computer program for estimating soil hydraulic parameters with hierarchical pedotransfer functions, J. Hydrol., 251, 163-176, 2001.

Schmidt, M.: TERENO (Eifel-Rur), Eddy Covariance/Climate station Rollesbroich 1, Germany, GFZ Data Services, doi:10.5880/TERENO.2016.004, 2016.

Seneviratne, S. I., Corti, T., Davin, E. L., Hirschi, M., Jaeger, E. B., Lehner, I., Orlowsky, B., and Teuling, A. J.: Investigating soil moisture-climate interactions in a changing climate: A review, Earth-Sci. Rev., 99, 125-161, 2010.

Smith, M. B., Seo, D. J., Koren, V. I., Reed, S. M., Zhang, Z., Duan, Q., Moreda, F., and Cong, S.: The distributed model intercomparison project (dmip): Motivation and experiment design, J. Hydrol., 298, 4-26, 2004.
Thompson, S. E., Harman, C. J., Troch, P. A., Brooks, P. D., and Sivapalan, M.: Spatial scale dependence of ecohydrologically mediated water balance partitioning: A synthesis framework for catchment ecohydrology, Water Resour. Res., 47, W00J03, doi:10.1029/2010WR009998, 2011.

van Genuchten, M. T.: A closed-form equation for predicting the hydraulic conductivity of unsaturated soils, Soil Sci. Soc. Am. J., 44, 892-898, 1980.

Vasilenko, N. G.: Water balance of small russian catchments in the southern mountainous taiga zone: "Mogot" case study, in: Northern research basins water balance, edited by: Kane, D. L. and Yang, D., Vol. 290, Wallingford, Int. Assoc. Hydrological Sciences, 65-77, 2004.

Vereecken, H., Huisman, J. A., Bogena, H., Vanderborght, J., Vrugt, J. A., and Hopmans, J. W.: On the value of soil moisture measurements in vadose zone hydrology: A review, Water Resour. Res. 44, 1-21, doi:10.1029/2008WR006829, 2008.

Western, A. W., Grayson, R. B., and Bloschl, G.: Scaling of soil moisture: A hydrologic perspective, Annu. Rev. Earth Planet. Sc., 30, 149-180, 2002.

Zacharias, S., Bogena, H., Samaniego, L., Mauder, M., Fuss, R., Puetz, T., Frenzel, M., Schwank, M., Baessler, C., ButterbachBahl, K., Bens, O., Borg, E., Brauer, A., Dietrich, P., Hajnsek, I., Helle, G., Kiese, R., Kunstmann, H., Klotz, S., Munch, J. C., Papen, H., Priesack, E., Schmid, H. P., Steinbrecher, R., Rosenbaum, U., Teutsch, G., and Vereecken, H.: A network of terrestrial environmental observatories in germany, Vadose Zone J., 10, 955-973, 2011. 